Evidence summaries

\title{
Self-management and patient activation in COPD patients: An evidence summary of randomized controlled trials
}

\author{
Uday Narayan Yadav ${ }^{\mathrm{a}, *}$, Hassan Hosseinzadeh $^{\mathrm{b}}$, Kedar Prasad Baral ${ }^{\mathrm{c}}$ \\ a ICCO Coalition for HIV/AIDS and SRHR- SSS, Kathmandu, Nepal \\ ${ }^{\mathrm{b}}$ School of Public Health and Community Medicine, Faculty of Medicine, University of New Southwales, Australia \\ ${ }^{\mathrm{c}}$ Department of Community Health Sciences, Patan Academy of Health Sciences, Kathmanud, Nepal
}

\section{A R T I C L E I N F O}

\section{Article history:}

Received 21 August 2017

Received in revised form 7 October 2017

Accepted 12 October 2017

Available online 13 October 2017

\section{Keywords:}

Patient activation

Chronic Obstructive Pulmonary Disease

(COPD)

Self-management

\begin{abstract}
A B S T R A C T
Background: Chronic Obstructive Pulmonary Disease (COPD) is associated with multiple health problems including physical and psychological impairment as well as socioeconomic deprivation. COPD can be managed if self-management efficiency and disease management knowledge of patients is improved. Patient activation is believed to improve patients' quality of life (QOL) and health outcomes through enhancing self-management skills. This review is an attempt to identify the benefits and knowledge gaps in self-management and patient-activation position in COPD self-management interventions Methods: Four electronic databases (Medline, Pubmed, Google Scholar and Cochrane Airways Group Specialized Register of Trials) were systematically searched from 1 January 2011 to 30 November 2016. The search strategy included the combined use of Medical

Subject: Headings (MeSH) term, which are as follows; "Self-management", "Self-care", "Self-treat", "Pulmonary disease", "Chronic Obstructive Pulmonary Disease", "Patient activation", "Patient Activation Measure", "Personalized support", "Chronic Obstructive Pulmonary Disease", "COPD”. The screening of the abstracts and full texts of the papers, data extraction and quality assessment were independently done by three reviewers.

Results: The results of this review showed that health outcomes (QOL, perceived quality of care, knowledge and severity on disease, lower rate of exacerbation, patient activation level) can be improved by self-management interventions with well cleared content on self-care guidelines and targeted behavior change models that possibly can increase self-efficacy of the patients. However, most of the studies have not applied patient activation which is shown to play a central role in COPD selfmanagement behaviors.

Conclusions: This review has identified that there is paucity of literature on patient activation in tailored COPD self-management intervention. As a way forward, there is need to test a well-designed randomized controlled trial considering key points like patients characteristics, compliance, intervention delivery period, multi-morbidity conditions and measurement of the outcomes with standardized tools, might help to arrive at enable scientific conclusions.
\end{abstract}

(c) 2017 Published by Elsevier, a division of RELX India, Pvt. Ltd on behalf of INDIACLEN.

\section{Background}

Chronic Obstructive Pulmonary Disease (COPD) was the fifth leading cause of death in 2002 and is estimated to be the third by 2030 worldwide. ${ }^{1}$ According to Global Burden of Disease (GBD) study, COPD was responsible for about $5 \%$ of global disabilityadjusted life years - DALYs (76.7 million) - and 5\% of total deaths

\footnotetext{
* Corresponding author at: ICCO Coalition for HIV/AIDS and SRHR- SSS, Kathmandu, Nepal.

E-mail address: unyadav1@gmail.com (U.N. Yadav).
}

(2.9 million). ${ }^{2}$ COPD is now prevalent in high-income countries as well as low and middle income countries, mainly due to smoking and exposure to risk factors like second-hand smoke, occupational dust and particles, and noxious gases. ${ }^{1,3}$

The treatment and management of chronic health conditions such as COPD is the most significant challenge for health systems around the globe. ${ }^{4}$ There is a wealth of evidence suggesting that self-management interventions improve patient outcomes. ${ }^{5}$ Self-management behaviors refer to the practices of activities that individuals initiate and perform on their own behalf in the interest of maintaining and continuing health and well-being. ${ }^{6}$ COPD self-management behaviors primarily involve self- 
recognition and self-treatment of exacerbation, taking medication and eating a healthy diet, coping with breathlessness, quitting smoking and taking regular exercise. ${ }^{7}$ A recent systematic review suggests that COPD self-management interventions are associated with improved patient outcomes and reduction in COPD specific health costs. ${ }^{7,8}$ However, several international studies have reported that COPD patients often do not receive optimal support from health professionals and therefore, are less likely to be involved in self-management activities. ${ }^{9-13}$

Patient's activation level (patient engagement in self-management) is measured by the Patient Activation Measure (PAM), which indicates the degree to which person is willing or able to engage in management of his/her health conditions. ${ }^{14}$ Activation involves four stage: (i) believing in the patient role, (ii) building patient confidence and knowledge for self-care, (iii) taking action to maintain and improve one's health and, (iv) staying the course even under stress. ${ }^{15,16}$ Thus, measurement of patient activation indicates patient knowledge, skill, and confidence for selfmanagement of long-term disease as well as the strategies to develop skills and build confidence. PAM is also an indicator ways to improve the processes that support self-management to obtain positive health outcomes.

In the chronic illness care model, patient activation is a central concept but is the least well- developed component. Several reviews which focused on patient tailored interventions have suggested that patient activation lead to improvements of health outcomes in a number of chronic conditions. ${ }^{9,17-19}$ Primary studies conducted among the COPD patients focusing on patient activation are available but there is no review level evidence available in this part. Therefore, this review was undertaken to synthesize evidence on patient activation in COPD self-management, with implications for future research. This document summarizes current evidence based on presented review question.

\subsection{The Review Question}

What are the benefits and knowledge gaps in self-management and patient-activation position in COPD self-management interventions?

\section{Methods}

Evidence summary of randomized controlled trial (RCT) was carried out to synthesize the findings.

\subsection{Search Strategy}

A search was carried out in four electronic databases (Medline, Pubmed, Google Scholar and Cochrane Airways Group Specialized Register of Trials).

\subsubsection{Self-management}

Databases were searched for articles published between 1 January 2011 and 30 November 2016. The search terms included the combined use of Medical Subject Headings (MeSH) term, which are as follows; "Self-management", "Self-care", "Self-treat", "Pulmonary disease", "Chronic Obstructive Pulmonary Disease", “COPD".

\subsubsection{Patient activation}

Databases were searched for articles published from 1 January 2004 up to 30 November 2016, as the PAM was not developed until

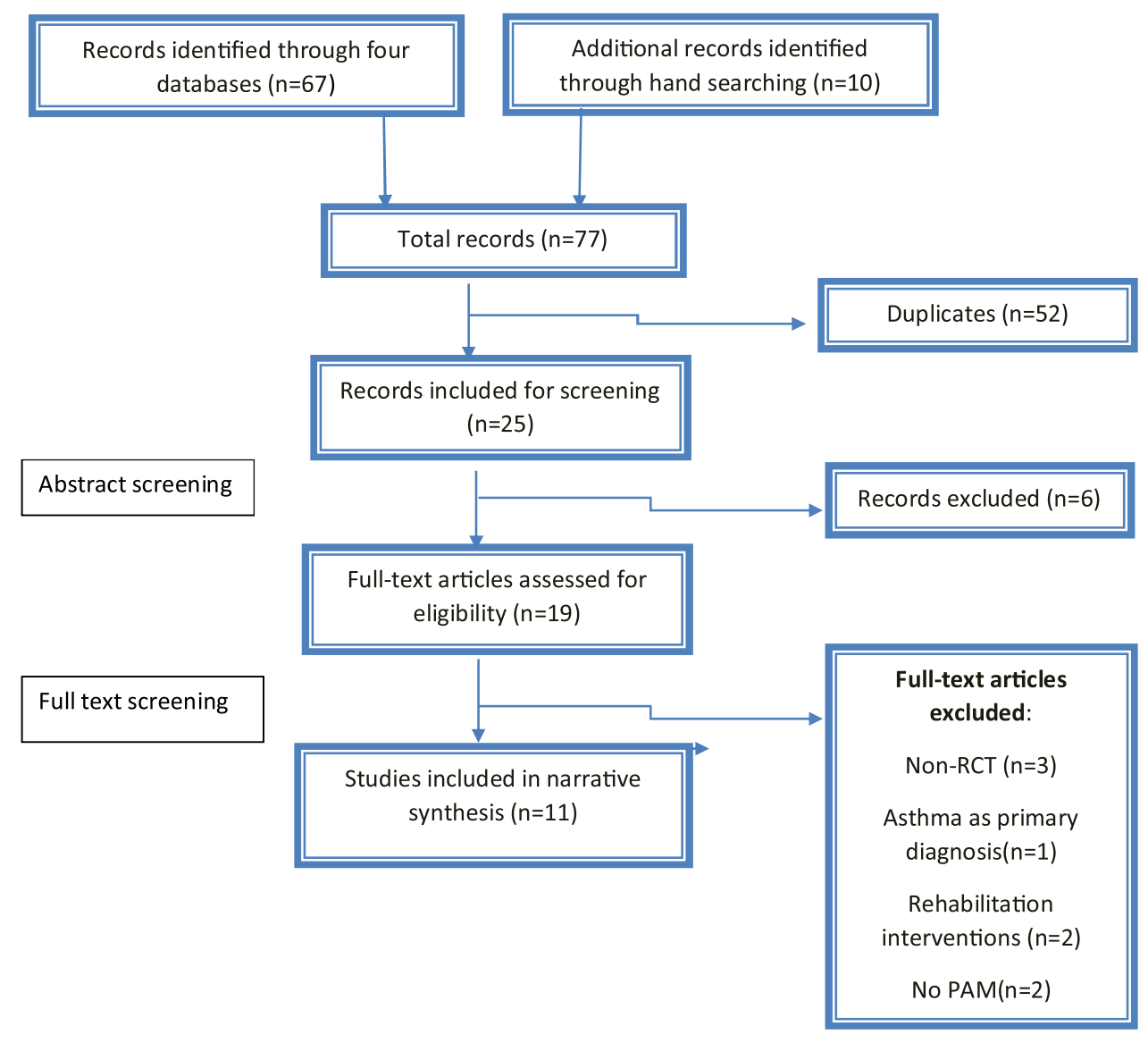

Fig. 1. Flow diagram of screening process. 
2004. The search combination used following MeSHterms: "Patient activation", "Patient Activation Measure", "Personalized support”, "Chronic Obstructive Pulmonary Disease”, “COPD”.

\subsection{Inclusion criteria}

Human subjects involving RCT were included, provided that full texts were accessible and available in English language. Participants had to be diagnosed with COPD irrespective of other co-morbidities and age restriction. Interventions had to be selfmanagement and patient activation of COPD patients. There was no restriction on comparison group.

Outcomes measures include: Quality of life (QOL), anxiety and depression, perceived quality of care, health service utilization, severity and duration of exacerbations, symptom burden and disease knowledge, patient activation measure.

\subsection{Exclusion criteria}

We excluded those RCTs which considered patients having asthma as the primary diagnosis and rehabilitation tailored interventions. Conferences abstracts, posters, published protocols, pharmacological, or animal studies were also excluded.

\subsection{Data extraction and analysis}

The screening of the abstracts and full texts of the papers, data extraction and quality assessment were independently done by three reviewers. Disagreement was resolved by discussion until consensus between the reviewers was reached. Information extracted included participant details, intervention details, outcome details, and time of follow up. Data were summarized according to the outcomes of interest for our study and separated into self-management and patient activation approaches. Narrative synthesis was undertaken to analyze the data.

\section{Results}

The search identified 67 full text articles from four databases and an additional 10 were identified by hand searching. From the citation yield 25 articles were in line with our criteria of selfmanagement and patient activation in COPD. Of the 25 studies, six were excluded, leaving 19 for full-text screening. From these articles, another eight were excluded for the following reasons; non-RCT $(n=2)$, asthma as primary diagnosis $(n=1)$, studies having rehabilitation interventions $(n=2)$. Two were excluded because patient activation outcome assessed was not appropriate. Our screening process is depicted in Fig. 1 below. Fig. 2 depicted the framework patient activation.

\subsection{Characteristics of included studies}

We divided the studies by self-management and selfmanagement with patient activation interventions.

\subsubsection{Self-management intervention}

Nine RCTs are identified under this group, involving a total of 2864 COPD patients. The characteristics of the included studies are presented in Table 1. Of the included studies, five studies reported follow-up time 12 months or more.

\subsubsection{Patient Activated intervention:}

Two RCTs are included which recruited a total of 1123 COPD patients, followed them for six months. The characteristics of included studies are depicted in Table 2.

\section{The Evidence}

\subsection{Outcomes of self-management Intervention}

\subsubsection{Quality of life}

HRQol was assessed by seven studies..$^{20,21,23-25,28,30}$ Most trials with follow-up of 6 months or more, showed significantly higher HRQoL in the intervention group compared to nonintervention group with usual treatment. Multicomponent interventions containing exercise counselling showed significant effects on HRQoL but those without exercise support demonstrated no improvement in HRQoL. The disease specific instruments for measurement (SGRQ) were used in five studies, ${ }^{21,23-25,28}$ of which two studies showed significant improved QOL in intervention group. There was wide variation in the tools adopted to measure outcome.

\subsubsection{Self-efficacy}

The effects of self-efficacy in COPD self-management were measured in four studies $21,22,25,27$ but no statically significant change was observed in any of them. None of the studies in our review focused on content on self-care guidelines and strategy for developing self-confidence among patients.

\subsubsection{Perceived quality of care}

Assessment of perceived quality of care by the Patient Assessment of Chronic Illness Care (PACIC) by all three studies $^{20,23,25}$ showed statistically significant change in the total score in the intervention group compared to control group. The results from these studies showed that interventions improved perceptions of overall care as well as patient activation, particularly in decision support and goal setting. However, two studies ${ }^{20,23}$ showed no effect on the dimensions of, problem-solving/contextual counselling and follow-up/coordination of care.

\subsubsection{Anxiety and depression}

Three studies ${ }^{22,24,26}$ quantified anxiety and depression as an outcome. Two of these studies lack effects regarding anxiety and depression because authors have not targeted anxiety and depression specifically. Remarkably, the study ${ }^{22}$ having coping as one of the important aspects of multicomponent interventions showed improvement in anxiety and depression level in the intervention arm compared to usual care.

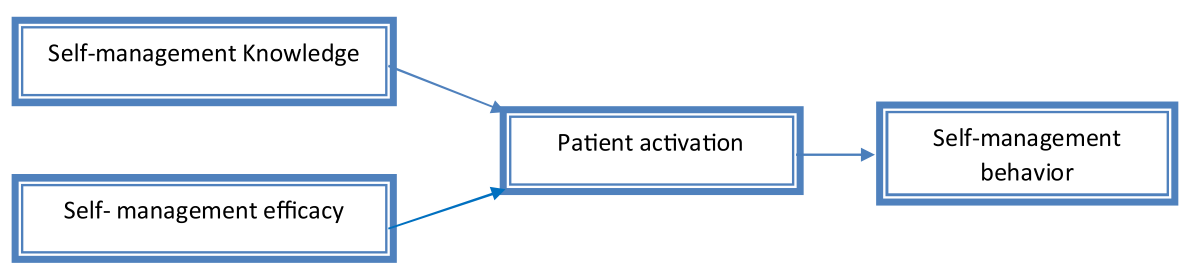

Fig. 2. Patient activation framework (Adopted from Do et $\mathrm{al}^{31}$ ). 
Table 1

Characteristics of the RCTs on self-management of COPD.

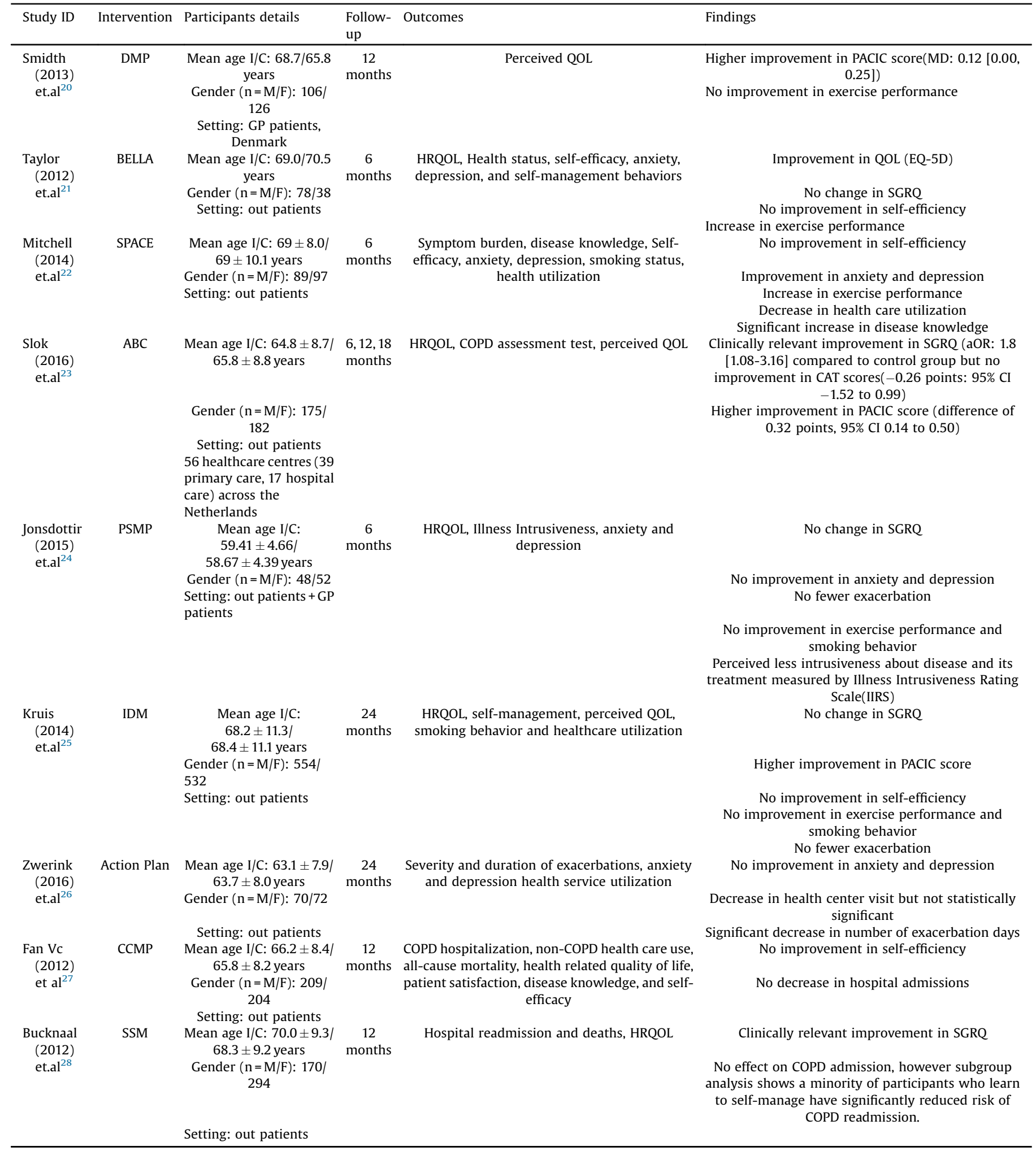

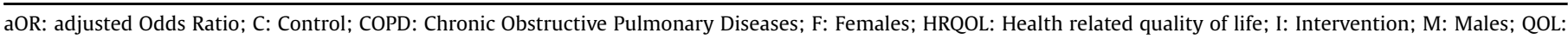

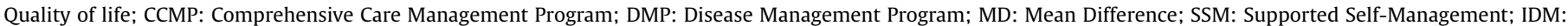

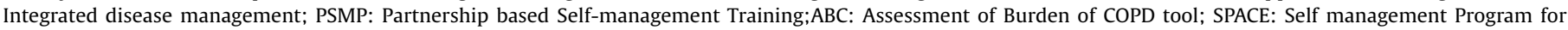
Activity, Coping and Education; BELLA: Better Living with Long-term Airways Disease. 
Table 2

Characteristics of the RCTs on patient activation in COPD.

\begin{tabular}{|c|c|c|c|c|c|}
\hline Study ID & Intervention & Mean age $\mathrm{I} / \mathrm{C}$ & $\begin{array}{l}\text { Follow-up (in } \\
\text { months) }\end{array}$ & Outcomes measured & Findings \\
\hline $\begin{array}{l}\text { Eikelenboom(2016) } \\
\text { et.al }^{29}\end{array}$ & SeMaS & $\begin{array}{l}\text { Mean age } \mathrm{I} / \mathrm{C}: 65.4 \pm 10.3 / \\
\quad 66.2 \pm 10.7 \\
\text { Gender ( } \mathrm{n}=\mathrm{M} / \mathrm{F}): 343 / 301 \\
\text { Setting: out patients }\end{array}$ & 6 month & $\begin{array}{l}\text { PAM-13, exercise, } \\
\text { smoking, }\end{array}$ & $\begin{array}{l}\text { Increased PAM and modeling shows positive } \\
\text { change in activation can improve variety of self- } \\
\text { management behaviours. } \\
\text { No change was observed in smoking behavior }\end{array}$ \\
\hline Hibbard (2007) et.al ${ }^{30}$ & CDSMP & $\begin{array}{l}\text { Mean age } I / C: \text { 59.6/60.0 } \\
\text { Gender }(n=M / F): 146 / 333\end{array}$ & 6 months & PAM, HRQOL & $\begin{array}{l}\text { Improved quality of life } \\
\text { PAM did not differ significantly, however per } \\
\text { protocol analysis shows the effect of the } \\
\text { intervention was significant on the number of } \\
\text { individual care plans and on self-monitoring }\end{array}$ \\
\hline & & Setting: out patients & & & \\
\hline
\end{tabular}

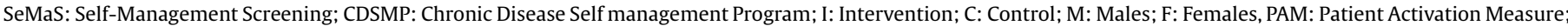
HRQOL: Health related quality of life.

\subsubsection{Smoking behavior}

The results from three studies ${ }^{24,25,29}$ showed no significant differences between intervention and group with usual care in line with smoking cessation. This is because the authors have not targeted smoking cessation specifically with incorporating behavior change model in the multicomponent intervention. Interestingly, the study by Mitchell et al. ${ }^{22}$, which aimed to support COPD patients by enhancing behavior change, showed significant improvment in smoking behavior.

\subsubsection{Health service utilization}

The effects of self-management on COPD patient's readmission/ visits were examined in five studies ${ }^{22,25-28}$ where three showed no reduction in hospital/health center visits or readmission. One study $^{22}$ having self-directed intervention within primary care showed results in favour of the intervention because of incorporation of self-management skills and disease-specific tasks.

\subsubsection{Symptom burden/disease knowledge}

The symptom burden and disease knowledge was assessed in two studies ${ }^{22,24}$ and the results are seen to favour the intervention. This is because interventions have provided adequate information on symptom and disease and thus, patients did not perceive their illness as negatively because they had better understanding.

\subsubsection{Duration and severity of exacerbations}

Three studies assessed the effects of intervention on management of exacerbations. Two studies recorded no decrease in exacerbations in the patients of intervention group compared to control group ${ }^{24,25}$ because the interventions lacked focused and clear content for management of exacerbation. A two year RCT ${ }^{26}$ with self-treatment of exacerbations as intervention showed that the median number of exacerbation days was significantly lower in the self-treated groups compared with the control groups.

\subsection{Outcomes of Patient Activation:}

\subsubsection{Patient Activation Measure}

Two studies quantified PAM as outcome in both the intervention and control group. One study ${ }^{30}$ reported an increase in activation is related to a positive change in a variety of selfmanagement behaviors and further, activation levels increased over time. The results also indicate that depression plays a central role in activation and in management of behavior, and those who are depressed are less likely to gain activation and improvement in their self-management behaviors. Another study ${ }^{29}$ assessed selfmanagement screening (SeMaS)tailored self-management intervention. The results revealed that there was no significant difference in PAM-13 score between the control $(n=348)$ and intervention $(n=296)$ arms at six months. The results of per protocol analyses revealed that the number of individual care plans and self-monitoring was significantly associated with intervention.

\section{Discussion}

To our knowledge, this review is the first to identify and analyze the benefits and knowledge gaps in self-management and patientactivation position in COPD self-management interventions. The results of this review show that health outcomes (QoL, perceived quality of care, knowledge and severity on disease, lower rate of exacerbation, patient activation level) can be improved by selfmanagement interventions with well cleared content on self-care guidelines and targeted behavior change models that can increase self-efficacy of the patients. However some studies do not support self-management interventions as effective strategies to reduce smoking behavior, decrease health service utilization, or improvement in anxiety and depression. ${ }^{32,33}$

Self-management interventions did improve perceived quality of care (PACIC) in COPD patients of intervention arm compared to that of control arm. ${ }^{20,23,25}$ This might be explained by the fact that self-management education may lead to better knowledge for goal setting, decision support, clinical information on disease and development of problem solving skills. ${ }^{34-38}$ Based on the evidence in the review this is clear that health education with high level of engagement between patients and responsive health care teams enhances the patient's capacity in seeking, understanding and acting on health information, thus bringing positive impacts on their health.

None of the studies in our review showed effect of interventions on self-efficiency. This could be the effect of a self-management programme that differed in content or provided inadequate skills to build self-confidence among the COPD patients. Improved patient engagement by building confidence and maintaining healthy behavior and, establishing supportive patient-health care professional relationship resulted in overall positive health outcomes. $^{39-41}$. In contrast, the review conducted by Cochrane group $^{9}$ showed that small positive pinning personalized care planning has an effect on self-efficacy. However, a study by Simpson et $\mathrm{al}^{42}$ demonstrated that higher levels of self-efficacy were associated with lower levels of breathlessness, anxiety and depression in COPD patients.

There is very limited literature on measured PAM as the primary outcome in multi-morbid COPD patients and few ongoing studies on patient activation in COPD patients. In the studies included (Table 2), Eikelenboom et $\mathrm{al}^{29}$ showed no significant difference in PAM-13 score between the control and intervention groups. In comparison, the study conducted by Hibbard et al $^{30}$ showed positive interaction between activation 
of patients and change in variety of self-management behaviors over a period of time. Research assessing the impact of interventions on patient activation is just beginning so there is need for robust work in this area since it is a gap in the literature and knowledge.

Within heterogeneity of self-management interventions, it is difficult to determine the most effective among them. The unique aspect of this research was that it has identified a number of limitations in the published research which need to be considered in future research. Most studies were not aimed at improving selfmanagement skills or behavior change but rather, focused on simply transferring knowledge and skills to patients expecting them to change behavior. Thus, it is equally important to help patients put knowledge and skills into practice in daily life rather than simply telling them what they need to do. In this review, we have evaluated a broad range of outcomes with different followup periods and it was observed that, outcomes were better in the studies that had longer period of flow-up i(.e minimum of 12 months). In this light, the Cochrane review has recommended that outcomes should be measured over the long term ( $>12$ months). ${ }^{6}$

Our review also identified that there is no uniformity in content and mode of delivery of intervention in line with selfmanagement. There was heterogeneity in tools used to measure the outcomes. For instance, some authors used SGRQ for measurement of quality of life in COPD patients while others used SF-8, EQ-5D, CCQ. Similarly, some studies used nonvalidated, self- constructed tools to measure variables like selfefficacy, Symptom/Disease Knowledge etc. There is no study on patient activation tailored self-management intervention solely for COPD patients. However, a few exist for the management of multi-morbid COPD patients. Additionally, no studies have looked into baseline assessment of depression symptoms in patients which might have an effect on study outcomes. Clearly, Atkins et al demonstrated how a cognitive-behavioral intervention increased physical exercise, which in turn improved Qol and selfefficacy in a large sample of COPD patients. ${ }^{43}$ There is need to access and address the depression symptoms in patient as they are less likely to gain activation and improvement in selfmanagement behaviors.

The interventions of this review showed improvement in QoL, perceived quality of care, knowledge and severity on disease and lower rate of exacerbation. However, many outcomes remained unchanged highlighting the need of further research. Additionally, few have focused on patient activation itself which always plays a central role in chronic care model. Moreover, among the studies in our review it is also the least well developed element. Increased evidence-based findings are needed to continue unraveling what constitutes successful self-management interventions. As a way forward, there is needs to be a well-designed randomized controlled trial considering key points like patient's characteristics, compliance, intervention delivery period, multi-morbidity conditions and measurement of the outcomes with standardized tools. This will be important for arriving at scientific conclusions on patient activation and self-management.

\section{Conflicts of interest}

\section{None}

\section{Acknowledgement}

The authors would like to thank Ms. Bishnu Kumari Ghimire (Executive Director, Sakriya Sewa Samaj, Kathmandu, Nepal) for providing financial support in this work.

\section{References}

1. WHO. The Global Burden of Disease 2004 update.[Internet]. World Health Organization; 2008 [Cited 2016 Nov 28]. Available from: http://www.who.int/ healthinfo/global_burden_disease/GBD_report_2004update_full.pdf..

2. Murray CJ, Vos T, Lozano R, Naghavi M, Flaxman AD, Michaud C, et al Disability?adjusted life years (DALYs) for 291 diseases and injuries in 21 regions, 1990-2010: a systematic analysis for the Global Burden of Disease Study. 2010. Lancet. 2012;380:2197-2223.

3. Global Initiative for Chronic Obstructive Lung Disease (GOLD). Global Strategy for the Diagnosis, Management and Prevention of COPD [Internet]. Global Initiative for Chronic Obstructive Lung Disease; 2016 [Cited 2 Dec 2016]. Available from: http://www.goldcopd.org/.

4. Guarascio AJ, Ray SM, Finch CK, Self TH. The clinical and economic burden of chronic obstructive pulmonary disease in the USA. Clinicoecon Outcomes Res. 2013;5:235-24510.2147/CEOR.S34321.

5. Vestbo J, Hurd SS, Agustí AG, Jones PW, Vogelmeier C, Anzueto A, et al. Global strategy for the diagnosis, management, and prevention of chronic obstructive pulmonary disease: GOLD executive summary. Am J Respir Crit Care Med. 2013:187(4)347-36510.1164/rccm.201204-0596PP Epub 2012 Aug 9.

6. Orem DE, Taylor SG, Renpenning KM. Nursing Concep Prac. 6th ed. St. Louis: Mosby; 2001402 p.

7. Zwerink M, Brusse-Keizer M, van der Valk PDLPM, Zielhuis GA, Monninkhof EM, van der Palen J, Frith PA, Effing T. Self management for patients with chronic obstructive pulmonary disease. Cochrane Database of Systematic Reviews 2014, Issue 3. Art. No. CD002990. [Cited 7]. Available from: http://www.cochrane.org/ CD002990/AIRWAYS_self-management-for-patients-with-chronicobstructive-pulmonary-disease..

8. Trappenburg J, Jonkman N, Jaarsma T, van Os-Medendorp H, Kort H, de WN, Hoes A, et al. Self-management: one size does not fit all. Patient Educ Couns. 2013;92:134-13710.1016/j.pec.2013.02.009 S0738-3991(13)00080-3 [pii], PMID: 23499381.

9. Coulter A, Entwistle VA, Eccles A, Ryan S, Shepperd S, Perera R. Personalised care planning for adults with chronic or long-term health conditions [Internet]. Cochrane Database Syst Rev. 2015;(Issue 3)10.1002/14651858. CD010523. pub2 Art. No.: CD010523 [Cited 4 June 2017].

10. Bos-Touwen I, Schuurmans M, Monninkhof EM, Korpershoek Y, SpruitBentvelzen L, Ertugrulvan der Graaf I, et al. Patient and Disease Characteristics Associated with Activation for Self- Management in Patients with Diabetes, Chronic Obstructive Pulmonary Disease, Chronic Heart Failure and Chronic Renal Disease: A Cross- Sectional Survey Study. PLoS ONE. 2015;5: e012640010.1371/journal.pone.0126400.

11. Nici L, Bontly TD, Zuwallack R, Gross N. Self-management in chronic obstructive pulmonary disease. Time for a paradigm shift? Ann Am Thorac Soc. 2014;11:101-10710.1513/AnnalsATS.201306-150FR PMID: 24460443.

12. Disler RT, Gallagher RD, Davidson PM. Factors influencing self-management in chronic obstructive pulmonary disease: an integrative review. Int J Nurs Stud. 2012;49:230-24210.1016/j.ijnurstu.2011.11.005 PMID: 22154095, S0020-7489 (11)00447-0 [pii].

13. Schoen C, Osborn R, Squires D, Doty M, Pierson R, Applebaum S. New 2011 survey of patients with complex care needs in eleven countries finds that care is often poorly coordinated. Health Aff (Millwood). 2011;12:2437-244810.1377/ hlthaff.2011.0923.

14. Silva De D. Helping people help themselves. A review of the evidence considering whether it is worthwhile to support self-management. Internet] Health Foundation; 2011 [Cited July 3, 2017]. Available from http://www.health.org. uk/sites/default/files/HelpingPeopleHelpThemselves.pdf.

15. Hibbard JH, Stockard J, Mahoney ER, Tusler M. Development of the Patient Activation Measure (PAM): Conceptualizing and Measuring Activation in Patients and Consumers. Health Serv Res. 2004;39(4 Pt 1):1005-1026.

16. Hibbard JH, Mahoney ER, Stockard J, Tusler M. Development and testing of a short form of the patient activation measure. Health Services Res. 2005;6(Pt 1):1918-1930.

17. Zwerink M, Brusse-Keizer M, van der Valk PD, Zielhuis GA, Monninkhof EM, van der Palen J. Self-management education for patients with chronic obstructive pulmonary disease. Cochrane Database Syst Rev. 2014:3:10.1002/ 14651858 CD002990. pub3.

18. Deakin TA, Mc Shane CE, Cade JE, Williams R. Group based training for selfmanagement strategies in people with type 2 diabetes mellitus. Cochrane Database Syst Rev. 2005;18(2)10.1002/14651858 CD003417. pub2.

19. Murray E, Burns J, See Tai S, Lai R, Nazareth I. Interactive Health Communication Applications for people with chronic disease. Cochrane Database of Syst Rev. 2005;19(4)10.1002/14651858 CD004274. pub4.

20. Smidth M, Olesen F, Gron MF, Vedsted P. Patient-experienced effect of an active implementation of a disease management programme for COPD - a randomised trial. BMC Family Practice. 2013;14:147p.

21. Taylor SJ, Sohanpal R, Bremner SA, Devine A, McDaid D. Fernández JL, et.al. Self-management support for moderate-to-severe chronic obstructive pulmonary disease: a pilot randomised controlled trial. Br J Gen Pract. 2012;62 (603):e687-e69510.3399/bjgp12x656829.

22. Mitchell KE, Warrington VJ, Apps LD, Bankart J, Sewell L, et al. A self management programme for COPD: a randomised controlled trial. Eur Respir J. 2014:44:1538-154710.1183/09031936.00047814.

23. Slok AHM, Kotz D, van Breukelen G, Chavannes NH, Molken MPMHR, Kerstjens HAM, et al. Effectiveness of the Assessment of Burden of COPD (ABC) tool on 
health-related quality of life in patients with COPD: a cluster randomised controlled trial in primary and hospital care. BMJ Open. 2016;6: e01151910.1136/bmjopen-2016-011519.

24. Jonsdottir $H$, Amundadottir OR, Gudmundsson $G$, Halldorsdottir BS, Hrafnkelsson B, Ingadottir TS, et al. Effectiveness of a partnership-based self-management programme for patients with mild and moderate chronic obstructive pulmonary disease: a pragmatic randomized controlled trial. J Adv Nurs. 2015;11:2634-264910.1111/jan.12728.

25. Kruis AL, Boland MRS, Assendelft J WJ, Gussekloo J, Tsiachristas A, Stijnen T, et. al. Effectiveness of integrated disease management forprimary care chronic obstructive pulmonary diseasepatients: results of cluster randomised trial. BMJ. 2014;349:g539210.1136/bmj.g5392.

26. Zwerink M, Kerstjens H, van der Palen Jvd, van der Valk P, Brusse-Keizer M, Zielhuis G. (Cost-)effectiveness of self-treatment of exacerbations in patients with COPD: 2 years follow-up of a RCT. Respirology. 2016;21:497-50310.1111/ resp.12697.

27. Fan VS, Gaziano M, Bourbeau J, Adams SG, Leatherman S, Thwin SS, et al. A compresensive care management program to prevent chronic obstructive pulmonary disease hospitalizations: A Randomized, Control Trial. Ann Intern Med. 2012;156(10):673-683.

28. Bucknall CE, Miller G, Lloyd SM, Cleland J, McCluskey S, Cotton M, et al, Glasgow supported self-management trial (GSuST) for patients with moderate to severe COPD: randomized controlled trial. BMJ. 2012;344:e106010.1136/ bmj.e1060.

29. Eikelenboom N, Van Lieshout J, Jacobs A, Verhulst F, Lacroix J, Van Halteren A, et al. Effectiveness of personalised support for self-management in primary care: a cluster randomised controlled trial. Br J Gen Pract. 2016;.

30. Hibbard JH, Mahoney ER, Stock R, Tusler M. Do Increases in Patient Activation Result in Improved Self-Management Behaviors? HSR: Health Serv Res. 2007;42(4):1443-1463.

31. Do V, Young L, Barnason S, Tran H. Relationships between activation level, knowledge, self-efficacy, and self-management behavior in heart failure patients discharged from rural hospitals [version 1; referees: 2 approved]. F1000Research. 2015;4:15010.12688/f1000research.6557.1.

32. Coventry PA, Bower P, Keyworth C, Kenning C, Knopp J, Garrett C, Hind D, et al. The effect of complex interventions on depression and anxiety in chronic obstructive pulmonary disease: systematic review and meta-analysis. PLoS One. 2013;4:e6053210.1371/journal.pone.0060532 Print 2013.

33. Jonker AA, Comijs HC, Knipscheer KC, Deeg DJ. Promotion of self-management in vulnerable older people: a narrative literature review of outcomes of the Chronic Disease Self-Management Program (CDSMP). Eur J Ageing. 2009;6 (4):303-314.

34. McCorkle R, Ercolano E, Lazenby M, Schulman-Green D, Schilling LS, Lorig K, et al. Self-Management: Enabling and empowering patients living with cancer as a chronic illness. CA Cancer J Clin. 2011;1:50-62.

35. Effing T, Monninkhof EE, van der Valk PD, van der Palen J, van Herwaarden CL, Partidge MR, et al. Self-management education for patients with chronic obstructive pulmonary disease. Cochrane Database Syst Rev. 2007;4(October (17)):CD002990.

36. Walters JA, Turnock AC, Walters EH, Wood-Baker R. Action plans with limited patient education only for exacerbations of chronic obstructive pulmonary disease. Cochrane Database Syst Rev. 2010;5:CD005074.

37. Barlow J, Wright C, Sheasby J, Turner A, Hainsworth J. Self-management approaches for people with chronic conditions: a review. Pat Educ Counsel. 2002;48:177-187.

38. Benzo R. Collaborative self-management in chronic obstructive pulmonary disease: learning ways to promote patient motivation and behavioral change. Chron Respir Dis. 2012;9:257-258.

39. Heje HN, Vedsted P, Olesen F. A cluster-randomized trial of the significance of a reminder procedure in a patient evaluation survey in general practice. Int $J$ Oual Health Care. 2006;18:232-237.

40. Vedsted P, Heje HN. Association between patients' recommendation of their GP and their evaluation of the GP. Scand J Prim Health Care. 2008;26:228-234.

41. Ansari RM, Hosseinzadeh H, Zwar N. Primary Healthcare System of Pakistan: Challenges to Self-Management of Type 2 Diabetes. Open J Endocr Metabol Dis. 2016;6:173-182.

42. Simpson E, Jones FC. An exploration of self-efficacy and self-management in COPD patients. Br J Nurs. 2013;19:1105-1109 Oct 24-Nov 13.

43. Atkins CJ, Kaplan RM, Timms RM, Reinsch S, Lofback K. Behavioral exercise programs in the management of chronic obstructive pulmonary disease. $J$ Consult Clin Psychol. 1984;52:591-603. 